\title{
Optimizing Open Access Policy
}

\author{
Stevan Harnad \\ Canada Research Chair in Cognitive Sciences, Université du Québec à Montréal \\ \& \\ University of Southampton
}

\begin{abstract}
This overview of the current status of Open Access (OA) to peer-reviewed research describes the steps that need to be taken to achieve universal OA. OA policy initiatives by universities and funding agencies as well as adaptations by publishers have resulted in some progress toward universal OA, but a significant portion of research remains inaccessible to its would-be users because of subscription barriers. Institutions are forced to support both journal subscriptions and Gold OA author publication fees. This is not affordable or sustainable. More and stronger OA mandates will accelerate the provision of universal Green $\mathrm{OA}$ and an eventual transition to affordable, sustainable Gold OA, in which author fees replace institutional subscription fees to cover the remaining essential costs of journal publication. To accelerate progress, more institutions and funders need to adopt more effective OA mandates: All universities and funders should require (1) institutional deposit (2) immediately upon acceptance for publication; urge (but not require) (3) immediate OA and (4) rights-retention; (5) minimize allowable embargo length, (6) implement the copy-request Button; (7) provide rich usage and citation metrics and (8) designate repository deposit of publications as the locus for institutional performance review as well as funding applications and renewals.
\end{abstract}

\section{Overview of Open Access (OA)}

Open Access (OA) means free online access to peer-reviewed research journal articles. There are about 40,000 such journals, in all fields and languages, publishing about 2.5 million articles per year. Most research journals recover their publication costs through institutional subscriptions. No institution can afford to subscribe to all or even most of the 40,000 journals (not even Harvard). Most institutions can only afford a small fraction of them -- a fraction that is shrinking because of rising journal costs.

As a result, all researchers today, at all institutions, are denied access to articles published in those journals whose subscriptions are unaffordable to their institutions. As a further result, the research that is funded by public tax revenue, and conducted by researchers employed by publicly funded institutions (universities and research institutes) is not accessible to all of its primary intended users - the researchers who can use, apply and build upon it (Gargouri et al 2010) to the benefit of the public that funded it.

The Internet and the Web have made it possible to remedy this access-denial 
problem, which had been a legacy of the Gutenberg era of print on paper, and its associated costs. Researchers can continue to publish their research in subscription journals, but they can, in addition, self-archive their final, peerreviewed drafts in their institutional repositories (Harnad 1995), as a supplement, for all users whose institutions cannot afford subscription access to the journal in which the article was published. Author self-archiving is called "Green OA" to distinguish it from the other way to provide $O A$, which is to publish in a journal that makes its own articles OA ("Gold OA"; Harnad et al 2004). (About 25\% of journals are Gold OA today, many of them recovering their costs by charging authors for publication instead of charging user institutions for subscription.)

About seventy percent of subscription journals (i.e., of non-OA journals, which still include most of the top journals in most fields) agree formally to Green OA self-archiving by their authors, some immediately upon publication, others after an embargo or delay on making the self-archived draft OA for 6-12 months or longer; the publisher rationale for the embargo is that it protects journal subscription revenues that Green OA might otherwise make unsustainable. It is likely that once Green OA has reached $100 \%$ globally it will indeed go on to make subscriptions unsustainable (Harnad 2014), although there is as yet no evidence (Swan \& Brown 2005) that immediate, un-embargoed Green OA self-archiving reduces subscriptions, even in fields, such as physics, where it has been practiced for over 20 years at a level that has long been close to $100 \%$.

Moreover, even if and when Green OA does go on to make subscriptions unsustainable as the means of recovering the cost of publication, subscription journals can then cut costs, downsize (Harnad 2007) and convert to an alternative cost-recovery system (Harnad 2013) that already exists and is already being piloted by over 10,000 journals: This second way to provide OA is for the journal rather than the author to make all of its articles freely accessible online immediately upon publication. This is the form of journal publishing that has been dubbed "Gold OA."

About $25 \%$ of the world's 40,000 peer-reviewed journals are Gold OA journals today, but very few of them are among the top journals in their fields. Many Gold OA journals continue to cover their costs either from subscriptions (to the print or online edition) or from subsidies; but the top Gold OA journals have no print edition and instead of charging the user-institution for access, through subscription fees, they charge the author-institution for publishing, through publication fees. There are also hybrid subscription/Gold journals that publish non-OA articles and continue to charge institutional subscription fees, but offer authors the option of paying to make their individual article OA if they pay a Gold OA publication fee.

Paying Gold OA fees today, however, is a problem for authors and their institutions because as long as most journals are still subscription journals, institutions have to continue subscribing to whatever journals they can afford from among those that their users need. Hence paying for Gold OA today increases the financial burden on institutions at a time when subscription costs 
are already barely affordable (Harnad 2012, 2013a). Moreover, not only is it an extra financial burden to pay for Gold OA today, while subscriptions still need to be paid, but it is also unnecessary, because Green OA can be provided for free while worldwide subscriptions are still paying the cost of publication.

If and when Green OA becomes universal, and if and when that, in turn, makes subscriptions unsustainable, then all journals can convert to Gold and institutions will have the money to pay the Gold OA costs out of their annual windfall subscription cancelation savings (Harnad, 2007; 2010). There is every reason to believe that Gold OA costs after universal Green OA will be much lower than they are today (Houghton \& Swan 2013): the print edition and its costs as well as the online edition will be gone, the worldwide network of Green OA Institutional Repositories will provide access and archiving, and journals will only need to manage peer review (all peers already review for free) (Harnad 2013b, 2014).

It remains to explain how to achieve universal Green $O A$, in order (1) to provide $\mathrm{OA}$, first and foremost, and then (2) to induce a transition to universal Gold OA at an affordable price if and when Green OA makes subscription publishing unsustainable, and (3) to release the institutional subscription funds in which the potential money to pay for Gold OA is currently locked.

The way to achieve universal Green OA is for institutions (universities and research institutes) and research funders to mandate (require) that all research that they fund, and that they employ researchers to conduct, must not only be published, as now ("publish or perish"), but that the peer-reviewed final drafts must also be deposited in the researcher's institutional repository immediately upon acceptance for publication.

Optimally, access to the immediate-deposit should also be made OA immediately. However, if necessary, an embargo of 6 months or even 12 months or longer can be tolerated for the time being in the case of the articles published in journals that do not endorse immediate Green OA if the author wishes to comply with the publisher OA embargo. The repository software has a "request-a-copy Button" that makes it possible for authors to provide "Almost-OA" to the deposits that are under OA embargo (Sale et al 2014). Any would-be user can press the Button to request a copy. The request is automatically forwarded via email to the author, who can then decide for each individual request received, with one click, whether or not a copy of the deposited article should be emailed to the requester by the repository software. Researchers have been fulfilling reprint requests from fellowresearchers for over a half century, but in the online era this can be greatly facilitated and accelerated as long as immediate-deposit is mandated.

\section{Funder and Institutional OA Mandates}

Twenty years of evidence have by now shown clearly that -- except in the very few subfields (such as computer science and physics) that self-archive spontaneously, unmandated -- the only way to get peer-reviewed journal articles to be made OA is to mandate (require) that they must be made OA. 
In 2003, the University of Southampton School of Electronics and Computer Science adopted the world's first Green OA self-archiving mandate (requirement). In 2004, the UK Parliamentary Select Committee recommended that UK universities and UK funding councils mandate Green OA self-archiving. Since 2004, Green OA self-archiving has been mandated by funding agencies and universities in the US, EU, Canada, and Australia. By mid-2015, over 600 Green OA mandates have been adopted worldwide, about $1 / 6$ of them by funders and $5 / 6$ by universities. In the US alone, the National Institutes of Health plus 33 other US funding agencies have mandated OA, as have Harvard, MIT and 119 other US universities and research institutions.

In 2013 the UK Higher Education Funding_Council proposed to mandate that in order to be eligible for research evaluation all peer-reviewed journal articles submitted must be deposited in the author's institutional repository immediately upon acceptance for publication, regardless of whether the article is published in a subscription journal or in a Gold OA journal (no preference, and no restriction on author's journal choice) -- and regardless of whether the publisher allows authors to set access to the immediate-deposit as OA immediately or imposes an OA embargo (for an allowable embargo period that remains to be decided)

To accelerate the worldwide growth of Green OA mandates all that is needed is $\underline{a}$ few practical upgrades in the Green OA mandate model adopted (Harnad 2012): systematic integration of institutional and funder mandates, systematic compliance verification mechanisms, incentives to deposit (such as download and citation metrics), and start-up help in depositing (Rentier \& Thirion 2012).

Institutions are the source of all peer-reviewed journal articles, in all fields, funded and unfunded. Authors who do not self-archive spontaneously, unmandated, cannot be expected to do it more than one time per article, in one place (rather than multiple times, in multiple places). The only parties that can systematically monitor and ensure that all authors' research output, in all fields, funded and unfunded, is self-archived, in compliance with self-archiving mandates, are authors' own institutions.

The only way institutions can systematically monitor and ensure that all of their own research output is self-archived is if it is all deposited, convergently, in their own institutional repository -- not if it is deposited, divergently, here and there, institution-externally. (The notion of institutions somehow locating and "backharvesting" their own institution-external content is so unrealistic that it is hardly worthy of serious discussion.)

The metadata of institutionally deposited articles can be -- and are being -harvested institution-externally by many search engines such as BASE (foremost among them being google and google scholar). The full-texts of institutional deposits are being harvested too (by google and google scholar and many others) -- although for most purposes users only need a link to the full-text in the institutional repository.

The power and functionality of OA harvesters can and will be enhanced 
dramatically -- but not until something closer to $100 \%$ of their target content is OA rather than today's $20-30 \%$. Till then it is simply not worth most developers' time and effort to enhance search functionality over such sparse content. This reinforces the need for effective OA self-archiving mandates, systematically (hence institutionally) monitored to ensure compliance.

The functionality of the 20-year old institution-external repository of physicists, Arxiv, does not come from the fact that its authors self-archive directly in Arxiv: it comes from the fact that its authors self-archive, and self-archive reliably (near $100 \%$ ), unmandated. (The same is true for those who share genomic or crystallographic data centrally, unmandated.)

Similarly, the functionality of PubMed Central (PMC), another institution-external repository (for biomedical research), does not come from the fact that its authors self-archive directly in PMC: it comes from the fact that its authors are mandated to self-archive. (The further $\mathrm{NIH}$ requirement that the deposit should be directly in PMC, and, worse, that it should be done by publishers rather than authors instead of just exporting authors' deposits from their institutional repositories - is not a functional advantage; it is a handicap and limitation on the scope and effectiveness of the NIH mandate model.)

But what is really holding up OA globally is that the vast majority of the target content is not being deposited at all -- either institutionally or institution-externally -- because Green OA itself has not yet been mandated globally: Immediate deposit of all peer-reviewed research output needs to be mandated by all institutions and funders worldwide. Immediate Open Access to the deposit would of course also be desirable, but, as noted above, the compromise of allowing OA to deposits to be embargoed (when there is the wish to comply with publisher embargoes on $\mathrm{OA}$ ) enables all institutions to adopt an effective mandate today, can provide about $60 \%$ immediate-OA plus $40 \%$ immediate Almost-OA, and will greatly accelerate (1) the demise of OA embargoes, (2) the attainment of universal Green OA, and (3) the eventual transition to affordable, sustainable Gold OA.

\section{Optimizing Green OA Mandates: Implementational Details}

The following are the eight most important features to ensure an effective, verifiable OA mandate:

1. All research funding agency OA Mandates need to specify clearly and explicitly that the deposit of each article must be in the author's institutional repository (so the universities and research institutions can monitor their own output and ensure compliance as well as adopt mandates of their own for their unfunded research output).

2. All mandates should specify that the deposit (of the authors refereed, revised, accepted final draft) must be done immediately upon acceptance for publication (not on the date of publication, which is often much later, variable, not known to the author, and frequently does not even 
correspond to the journal issue's published date of publication, if there is one) (Vincent-Lamarre et al 2015; Swan et al 2015).

3. All mandates should urge (but not require) authors to make their immediate-deposit immediately-OA.

4. All mandates should urge (but not require) authors to reserve the right to make their papers immediately-OA (and other re-use rights) in their contracts with their publishers (as in the Harvard-style mandates).

5. All mandates should shorten (or, better, not even mention) allowable OA embargoes (so as not to encourage publishers to adopt them).

6. All repositories should implement the automated "email eprint request" Button (for embargoed [non-OA] deposits).

7. All mandates should designate repository deposit as the sole mechanism for submitting publications for performance review, research assessment, grant application, or grant renewal.

8. All repositories should implement rich usage and citation metrics in the institutional repositories as incentive for compliance.

Once this optimal mandate model is adopted by funders and institutions worldwide, universal OA will soon follow -- and a global transition to affordable, sustainable Fair-Gold OA (instead of today's premature, double-paid Fool's-Gold) - and not far behind will be as many re-use rights as users need and authors wish to provide (Harnad 2013).

The compromise of allowing embargoes and mandating only immediate-deposit but not immediate-OA hastens and facilitates the universal adoption of immediate-deposit mandates by all institutions and funders. The institutional repositories' email-eprint-request Button is there to tide over user needs during embargoes.

The other essential compromise is not to insist prematurely on further rights -over and above free online access -- that publishers are not yet willing to allow, such as text-mining, re-mix and re-publication rights. First things first: Funders, institutions and authors should not prolong their failure to grasp what's already within their reach by over-reaching for what's not yet within reach: The perfect should not be allowed to become the enemy of the good.

With direct institutional deposit mandated, search engines and indexers can immediately harvest the metadata where and when they please, linking to the deposits, whether they are embargoed or OA. This separates the date on which deposit must be made (immediately upon acceptance for publication, with no differences across disciplines) from the date on which the deposit must be made OA (preferably immediately, but, at the latest, within an allowable embargo whose length will be adapted to the needs of each discipline). 
By making immediate-deposit (but not immediate-OA) an eligibility precondition for submission to research evaluation (HEFCE 2013), funding agencies recruit institutions to monitor and ensure timely compliance with their mandates.

Expressing no preference for gold OA publishing leaves authors free to publish in whatever journals they choose (and entails no extra costs) -- and expressing a preference for licensing certain re-use rights (but not requiring them) again leaves this to author choice.

Altogether, this blueprint for mandating Green OA is the simplest, fastest, cheapest and surest way to make mandates palatable and attractive to that missing $70 \%$ of authors who have so far failed to make their research freely accessible online, ever since the Web made it possible more than two decades ago. The result will be an end to the denial of access to the 2.5 million articles resulting from publicly funded research and published purely for the purpose of contributing to the productivity and progress of human inquiry.

\section{References}

Gargouri, Yassine, Larivière, Vincent \& Harnad, Stevan (2013) Ten-year Analysis of University of Minho Green OA Self-Archiving Mandate (in Eloy Rodrigues, Alma Swan \& Ana Alice Baptista, Eds. Uma Década de Acesso Aberto e na UMinho no Mundo. http://eprints.soton.ac.uk/358882/

Gargouri, Yassine, Lariviere, Vincent, Gingras, Yves, Carr, Les and Harnad, Stevan (2012) Green and Gold Open Access Percentages and Growth, by Discipline. In: 17th International Conference on Science and Technology Indicators (STI), 5-8 September, 2012, Montreal, Quebec, Canada, Montréal. http://eprints.soton.ac.uk/340294/

Gargouri, Yassine, Hajjem, Chawki, Lariviere, Vincent, Gingras, Yves, Brody, Tim, Carr, Les and Harnad, Stevan (2010) Self-selected or mandated, open access increases citation impact for higher quality research. PLoS ONE, 5, (10) http:// eprints.soton.ac.uk/268493/

Harnad, Stevan (2015) Open Access: What, Where, When, How and Why. In: Ethics, Science, Technology, and Engineering: An International Resource eds. J. Britt Holbrook \& Carl Mitcham, (2nd of Encyclopedia of Science, Technology, and Ethics, Farmington Hills MI: MacMillan Reference) http://eprints.soton.ac.uk/ $\underline{361704 /}$

Harnad, S (2014) The only way to make inflated journal subscriptions unsustainable: Mandate Green Open Access. LSE Impact of Social Sciences Blog 4/28 http://blogs.Ise.ac.uk/impactofsocialsciences/2014/04/28/inflatedsubscriptions-unsustainable-harnad

Harnad, S. (2013a). Harnad Evidence to BIS Select Committee Inquiry on Open Access. Written Evidence to BIS Select Committee Inquiry on Open Access. http://eprints.soton.ac.uk/348483/ 
Harnad, Stevan (2013b) The Postgutenberg Open Access Journal (revised). In, Cope, B and Phillips, A (eds.) The Future of the Academic Journal (2nd edition). 2nd edition of book Chandos. http://eprints.soton.ac.uk/353991/

Harnad, S (2012) United Kingdom's Open Access Policy Urgently Needs a Tweak. D-Lib Magazine Volume 18, Number 9/10 September/October 2012 http://www.dlib.org/dlib/september12/harnad/09harnad.html

Harnad, S. (2010) No-Fault Peer Review Charges: The Price of Selectivity Need Not Be Access Denied or Delayed. D-Lib Magazine 16 (7/8). http:// eprints.ecs.soton.ac.uk/21348/

Harnad, S. (2007) The Green Road to Open Access: A Leveraged Transition. In: Anna Gacs. The Culture of Periodicals from the Perspective of the Electronic Age. L'Harmattan. 99-106. http://eprints.ecs.soton.ac.uk/13309/

Harnad, Stevan. (1995) Universal FTP Archives for Esoteric Science and Scholarship: A Subversive Proposal. In: Ann Okerson \& James O'Donnell (Eds.) Scholarly Journals at the Crossroads; A Subversive Proposal for Electronic Publishing. Washington, DC., Association of Research Libraries, June 1995. http://www.arl.org/scomm/subversive/toc.html

Harnad, S., Brody, T., Vallieres, F., Carr, L., Hitchcock, S., Gingras, Y, Oppenheim, C., Stamerjohanns, H., \& Hilf, E. (2004) The green and the gold roads to Open Access. Nature Web Focus. http://www.nature.com/nature/focus/ accessdebate/21.html

HEFCE (2013) Higher Education Funding Council of England: Open Access Mandate Proposal. http://roarmap.eprints.org/834/

Houghton, John. \& Swan, Alma. (2013) Planting the Green Seeds for a Golden Harvest: Comments and Clarifications on "Going for Gold". D-Lib Magazine 19 (1/2). http://www.dlib.org/dlib/january13/houghton/01houghton.html

Rentier, B., \& Thirion, P. (2011). The Liège ORBi model: Mandatory policy without rights retention but linked to assessment processes. http://orbi.ulg.ac.be/handle/ $\underline{2268 / 102031}$

Sale, Arthur, Couture, Marc, Rodrigues, Eloy, Carr, Les and Harnad, Stevan (2014) Open Access Mandates and the "Fair Dealing" Button. In, Dynamic Fair Dealing: Creating Canadian Culture Online (Rosemary J. Coombe \& Darren Wershler, Eds.). , University of Toronto Press. http://eprints.ecs.soton.ac.uk/ $\underline{18511 /}$

Vincent-Lamarre, Philippe, Boivin, Jade, Gargouri, Yassine, Larivière, Vincent and Harnad, Stevan (2014) Estimating Open Access Mandate Effectiveness: I. The MELIBEA Score. (Submitted) http://eprints.soton.ac.uk/370203/

Suber, Peter (2008) Gratis and libre open access. SPARC Open Access 
Newsletter 124 http://dash.harvard.edu/handle/1/4322580

Swan, Alma and Brown, Sheridan (2005) Open access self-archiving: An author study. JISC Report. http://eprints.soton.ac.uk/260999/

Swan, Alma; Gargouri, Yassine; Hunt, Megan; \& Harnad, Stevan (2015) Open Access Policy: Numbers, Analysis, Effectiveness. Pasteur4OA Workpackage 3 Report. http://eprints.soton.ac.uk/375854/ 